\title{
Evaluation of binder blending on warm mix asphalt recycling
}

\author{
Matheus S. Gaspar ${ }^{1}$, Kamilla L. Vasconcelos ${ }^{2}$, Manuela M. Lopes ${ }^{3}$, Liedi L. B. Bernucci ${ }^{4}$ \\ 1Universidade de São Paulo, Escola Politécnica, matheus.gaspar@usp.br \\ 2Universidade de São Paulo, Escola Politécnica, kamilla.vasconcelos@usp.br \\ ${ }^{3}$ AME-EASE, Université Gustave Eiffel, IFSTTAR, manuela.gennesseaux@univ-eiffel.fr \\ ${ }^{4}$ Universidade de São Paulo, Escola Politécnica, liedi@usp.br
}

\section{Recebido:}

6 de agosto de 2019

Aceito para publicação:

17 de outubro de 2019

Publicado:

15 de abril de 2020

Editor de área:

Jorge Barbosa Soares

\section{Keywords:}

RAP,

Rheology,

Sustainability.

\section{Palavras-chaves:}

Material fresado,

Reologia,

Sustentabilidade.

DOI:10.14295/transportes.v28i2.2133

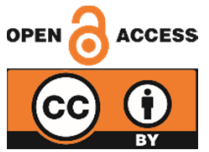

\begin{abstract}
It is still a challenge to produce recycled asphalt mixtures with increased contents of reclaimed asphalt pavement (RAP) without compromising field performance. On hot and warm recycling, the RAP binder is activated, but the amount that truly interacts with the fresh binder is unknown. The present study describes the application of a staged extraction laboratory procedure to evaluate the homogeneity of the binder film in two plant-produced warm mixtures, one containing 25\% RAP and the other without RAP (control mixture). The "layers" of binder obtained through the procedure were tested in the Dynamic Shear Rheometer. Results showed a progressive variation of the parameters for the 25\% RAP mixture, which was not observed for the control mixture. The procedure was useful to determine binder homogeneity in recycled mixtures, which can be related to the degree of blending between RAP and fresh binders, providing useful information to ensure adequate field performance.
\end{abstract}

\section{RESUMO}

A produção de misturas asfálticas com teores elevados de material fresado (RAP) sem prejuízo ao desempenho em campo ainda é um desafio. Nas reciclagens a quente e morna, o ligante presente no RAP é ativado, mas não se sabe quanto dele efetivamente interage com o ligante novo. Neste trabalho, é aplicado um procedimento laboratorial de extração por etapas que busca avaliar a homogeneidade do ligante asfáltico em duas misturas mornas produzidas em usina, uma delas com $25 \%$ RAP e a outra sem RAP (mistura de controle). As "camadas" de ligante obtidas foram testadas no Reômetro de Cisalhamento Dinâmico. Os resultados mostraram que, para a mistura com 25\% RAP, os parâmetros analisados variaram de forma progressiva, diferente da mistura de controle. O procedimento se mostrou útil para avaliar a homogeneidade do ligante, o que está relacionado ao grau de interação entre ligantes e pode ser usado para assegurar um bom desempenho.

\section{INTRODUCTION AND BACKGROUND}

Reclaimed asphalt pavement (RAP) has become a valuable material for the paving industry, due to the potential for reducing costs and the environmental benefits of using it in new layers of pavement. It is possible to apply this material in different ways, such as in granular layers or incorporating it to stabilized materials. When it is used in the surface layer, through hot and warm recycling processes, it can replace the most expensive materials, in particular the asphalt binder (Copeland, 2011). During hot and warm recycling RAP, binder is mobilized, or activated, therefore it can replace part of the asphalt binder that would be added to the mixture (Zaumanis e Mallick, 2015). However, applying high contents of RAP can be detrimental to field performance and one motive is the insufficient comprehension about the complex mechanisms that 
are involved in the blending between RAP and fresh binders (Lo Presti et al., 2016). The content of virgin asphalt binders is determined on mix design assuming a perfect blending between both binders, but previous studies have confirmed that what happens in practice is a partial blending (Shirodkar et al., 2011; Huang et al., 2005; Navaro et al., 2012; Zhao et al, 2015a).

Aiming to assess the degree of blending between binders, researchers have applied a laboratory procedure called staged or progressive extraction, in which the asphalt mixture is subjected to binder extraction in a way that sequential layers of binder are extracted and recovered, so that the homogeneity of the binder is analyzed (Zhao et al, 2015b). The binder homogeneity, in turn, can be used as an indicator of the level of blending between RAP binder and fresh binder, which is important to ensure adequate field performance of the recycled mixture, especially at high RAP contents. An illustration of the staged extraction process executed in three steps, as it is done in the present study, is provided in Figure 1.

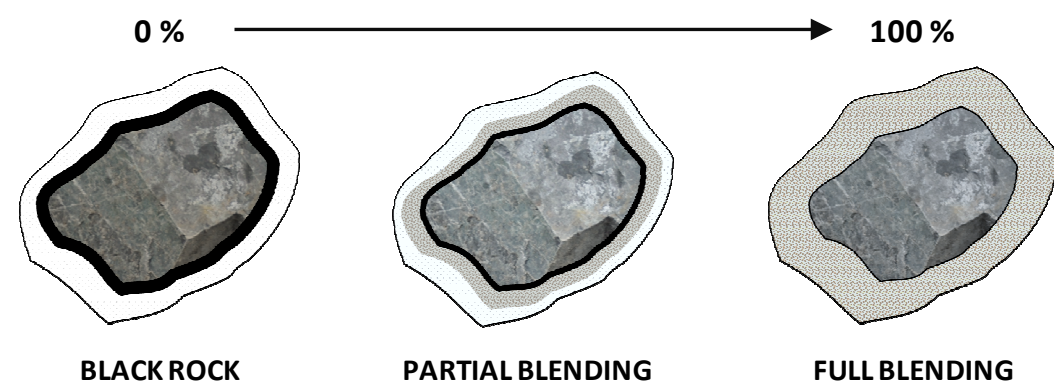

Figure 1. Illustration of the three blending scenarios

The staged extraction method was initially applied by Zearley (1979) to prove that the blending between binders was not homogeneous in a sample of RAP covered with virgin asphalt binder. The same approach was used in other studies in the 1980s to verify the blending between RAP binder and rejuvenating agents (Bowers et al., 2014a; Soleymani et al., 2000). The procedure was also used by Huang et al. (2005), who concluded that part of the RAP binder remains bonded to the aggregates instead of blending with the virgin binder. More recent studies applied the staged extraction process and analyzed the recovered binders using different methods, such as gel permeation chromatography, Fourier-transform infrared spectroscopy, UV spectroscopy and rheological tests, and confirmed that staged extraction is a useful tool to investigate the heterogeneity of the binder film in recycled asphalt mixtures (Bowers et al, 2015; Carpenter e Wolosick, 1980; Eddhahak-Ouni et al., 2012; Noureldin e Wood, 1987).

Despite the relevant findings of previous studies that applied the staged extraction method, these studies have used a variety of different procedures and equipments, what makes it difficult for other research groups to choose the best procedure and reliably reproduce them. From that perspective, a previous study by Gaspar et al. (2017) intended to develop and establish one staged extraction method using standard reflux extraction equipment. After preliminary tests, it was concluded that it is necessary to adjust the length of each of the extraction steps, to achieve more consistent results. With this scenario in mind, the present study aimed to assess the capability of the same staged extraction method, after adjusting the period of each step of extraction, to evaluate binder homogeneity in a recycled asphalt mixture containing $25 \%$ of RAP, produced at the plant, while comparing the results to those of a control mixture without RAP, produced at the same plant and with the same materials. 


\section{MATERIALS AND METHODS}

\subsection{Materials}

In this study, two plant-produced warm asphalt mixtures were used. Both mixtures were produced using basalt aggregates, a neat asphalt binder (penetration grade 30/45) and surfactant additive $(0.4 \%$ by weight of total binder). In one of the mixtures (WMA $25 \%$ RAP), $25 \%$ by weight of the aggregates were replaced by RAP, while the control mixture (WMA 0\% RAP) was produced without RAP. Hydrated lime was applied as filler and anti-stripping agent. The characterization of the new asphalt binder used is provided in Table 1.

Table 1 - Characteristics of the virgin asphalt binder

\begin{tabular}{lll}
\hline Parameter & Result & Requirements (Brazilian specification DNIT 095/2006) \\
\hline Penetration at $25^{\circ} \mathrm{C}(0.1 \mathrm{~mm})$ & 37 & $30-45$ \\
Softening point $\left({ }^{\circ} \mathrm{C}\right)$ & 53 & $\min .52$ \\
Flash point $\left({ }^{\circ} \mathrm{C}\right)$ & 350 & $\min .235$ \\
Density at $25^{\circ} \mathrm{C}\left(\mathrm{g} / \mathrm{cm}^{3}\right)$ & 1.008 & - \\
Brookfield viscosity at $135^{\circ} \mathrm{C}(\mathrm{cP})$ & 528 & $\min .374$ \\
Brookfield viscosity at $150^{\circ} \mathrm{C}(\mathrm{CP})$ & 248 & $\min .203$ \\
Brookfield viscosity at $177^{\circ} \mathrm{C}(\mathrm{cP})$ & 84 & $76-285$ \\
\hline
\end{tabular}

These asphalt mixtures were produced as part of another research study that aimed to evaluate the feasibility of using warm-mix asphalt technology to produce recycled mixtures with increased RAP contents in conventional batch plants in Brazil, and both were applied as surface layers in the rehabilitation of two test sections (Gennesseaux, 2015). For the present study, samples of the produced asphalt mixtures were collected, during field application, and taken to the laboratory. The RAP used was characterized prior to mix design, and the binder content was $5.0 \%$, as a result of the ignition test method (ASTM D6307-16). Further information about the materials characterization and mix design are available in Gaspar et al. (2019) and Lopes et al. (2016).

The binder content determined during mix design was 4.7\%, of total weight of mixture. For the mixture containing RAP, a full blending scenario was assumed, and the RAP binder replaced $25.3 \%$ of the virgin binder. Therefore, the virgin binder content added to the recycled mixture (WMA 25\% RAP) was 3.5\%, while the remaining 1.2\% were composed by the RAP binder. Mixtures were produced in a batch plant that was previously adapted for handling RAP materials. For the WMA 25\% RAP mixture, RAP was added to the mixture at ambient temperature, and was heated through the contact with the virgin aggregates, which were superheated at $180^{\circ} \mathrm{C}$. The mixing was conducted at $140^{\circ} \mathrm{C}$.

\subsection{Staged extraction and recovery}

The staged extraction method applied was based on the reflux extraction procedure (method B of the standard ASTM D2172-11). The same extraction apparatus was used (with one metal cone frame only, as represented in Figure 2a), but the standard extraction procedure was interrupted twice until the sample was fully washed. By the end of the first and second steps of extraction, the solution composed of trichloroethylene and asphalt binder was gathered and replaced by new solvent. That way, the asphalt binder that covered the aggregate particles of the sample is assumed to be split in three layers. As illustrated in Figure $2 b$, the external layer is 
extracted during the first step (Step 1 of extraction), and the internal layer is obtained in the final wash (Step 3 of extraction). Step 2 consists in the extraction of the intermediate layer of asphalt. The aim of this laboratory procedure is to evaluate the properties of the extracted layers and, from that, obtain an indication of the homogeneity of the binder layers, which is supposed to be related to the degree of blending of the binders.

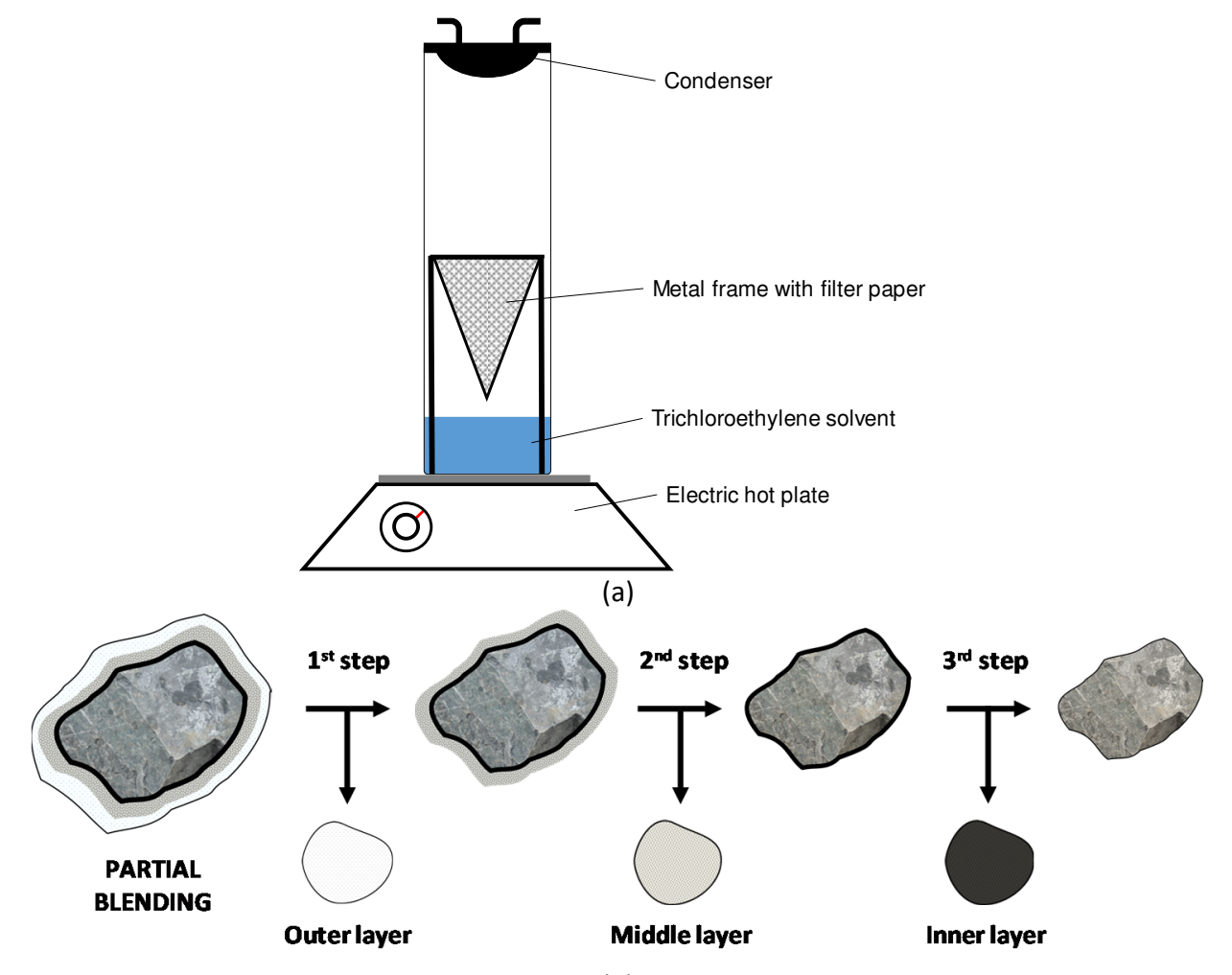

(b)

Figure 2. Illustration of (a) the extraction apparatus and (b) the staged extraction procedure

Inspired by studies available in the literature (Huang et al., 2005; Zhao et al., 2015b; Carpenter e Wolosick, 1980; Eddhahak-Ouni et al., 2012; Noureldin e Wood, 1987; Bowers et al., $2014 \mathrm{~b}$ ), the procedure is an effort to separate the layers of the binder in a more controlled way. The process applied was introduced in a previous paper by Gaspar et al. (2017), where it is described in more detail, and which concluded that the length of the extraction steps should be adjusted. In that case, the first and the second steps of extraction were conducted for 20 minutes each, counting from the moment the solvent began to drip from the condenser, and the third step was conducted until the aggregates were completely washed. However, more than half of the total binder in the sample was extracted already in the first wash, and only $18 \%$ was obtained in the third wash, after the binders were recovered through the Abson method (ASTM D1856-09). Since the idea was to obtain similar amounts of binder in each of the extraction steps, it was decided that an adjustment in the extraction times was needed. It was observed, however, that the rate of binder extraction can vary, depending on the asphalt mixture analyzed, so different extraction times might be necessary for different mixtures.

In this paper, staged extraction was conducted using three sets of reflux extraction equipment, that were used simultaneously. On each of them, $500 \mathrm{~g}$ of asphalt mixture was used, totalizing $1500 \mathrm{~g}$ of asphalt mixture. The samples were inserted in the metal cone frame, covered 
with filter paper, and each extraction set was placed on an electric hot plate, turned on at approximately $200^{\circ} \mathrm{C}$. The procedure was carried out during 10 minutes on Step 1 and 20 minutes on Step 2, for the WMA 25\% RAP mixture, and 5 minutes on Step 1 and 10 minutes on Step 2, for the WMA 0\% RAP mixture. For both mixtures the third and last extraction step was conducted until the aggregates were completely washed. These times were counted from the moment that the solvent began to drip from the condenser, in the top of the extraction apparatus, and were selected using trial and error. For these extraction times, the amount of binder obtained in each step is presented in Figure 3, being as close as possible to the ideal situation. After each step, the solution obtained was collected, passed in a laboratory centrifuge to remove fine aggregate residues, and the asphalt binder in each of them was recovered using the standard Abson recovery method ASTM D1856-09.

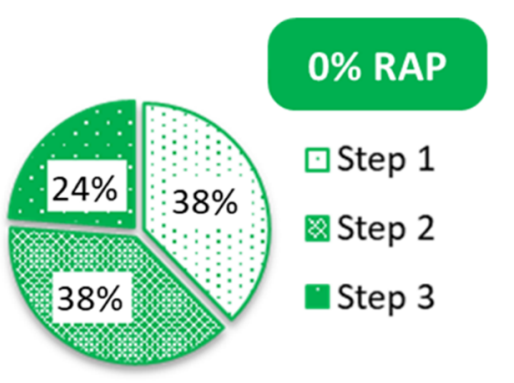

(a)

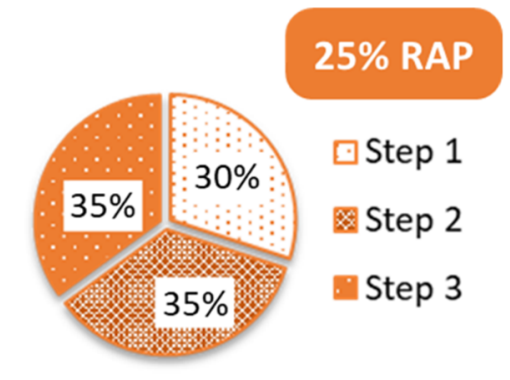

(b)

Figure 3. Relative amount of binder extracted and recovered at each step of the process for (a) WMA 0\% RAP and (b) WMA 25\% RAP

\subsection{Rheological tests}

The asphalt binders obtained from each extraction step, for both asphalt mixtures (WMA 0\% RAP and WMA 25\% RAP) were analyzed in the Dynamic Shear Rheometer (DSR), using temperature-frequency sweep oscillatory test. These tests, used to obtain the linear viscoelastic properties, dynamic shear modulus $\left(\left|G^{*}\right|\right)$ and phase angle $(\delta)$, were carried out from 0.1 to 10 $\mathrm{Hz}$ and from $5^{\circ} \mathrm{C}$ to $80^{\circ} \mathrm{C}$. Two parallel-plate geometries were used: $8 \mathrm{~mm}$ diameter with $2 \mathrm{~mm}$ gap for temperatures below $40^{\circ} \mathrm{C}$, and $25 \mathrm{~mm}$ diameter with $1 \mathrm{~mm}$ gap for temperatures above $40^{\circ} \mathrm{C}$. Tests were executed in strain-controlled mode $(0.1 \%$ strain), ensuring that the materials behavior was kept within the linear viscoelastic region. The recommendations provided in the specification ASTM D7175-15 were followed. The obtained data were used to construct master curves of dynamic shear modulus $\left|\mathrm{G}^{*}\right|$ and phase angle $\delta$, at the reference temperature of $15^{\circ} \mathrm{C}$.

The binders were also subjected to the Multiple Stress Creep and Recovery (MSCR) test and the Linear Amplitude Sweep (LAS) test, which are originally used to evaluate rutting and fatigue potential of asphalt binders, respectively. In the MSCR test (ASTM D7405-15), the sample is loaded with a constant creep stress for $1 \mathrm{~s}$ and rests for $9 \mathrm{~s}$, and this cycle is repeated 20 times for the stress level of $100 \mathrm{~Pa}$ (the first 10 for sample conditioning) and 10 times for the stress of 3,200 Pa. The parameters Jnr (non-recoverable compliance) and R\% (recovery) are reported at the end of the test, and indicate the susceptibility of the sample to rutting under a cyclic load, assessing its behavior when subjected to strain levels that take its behavior outside of the linear viscoelastic region. In this study, the MSCR tests were conducted at $70^{\circ} \mathrm{C}$. The temperature for the MSCR test was defined aiming to obtain values for the Jnr within the range that is more frequent on the evaluation of asphalt binders, which is between 1.0 and $4.0 \mathrm{kPa}^{-1}$. 
The LAS test is also applied to evaluate the behavior of the asphalt sample outside of the linear viscoelastic region, in order to evaluate fatigue cracking susceptibility of the asphalt binder. The test follows the AASHTO TP 101 procedure, and is performed in two steps. First, a frequency sweep is conducted, from 0.2 to $30 \mathrm{~Hz}$ and applying an oscillation strain of $0.1 \%$. Then, a linear amplitude strain sweep is applied (from 0 to 30\%) at $10 \mathrm{~Hz}$. The failure criterion was defined as the point where the maximum shear stress is reached. The fatigue curve, which is the final result of the test, is obtained by analyzing the obtained data through the simplified viscoelastic continuum damage (S-VECD) principle and calculating the damage characteristic curve ( $\mathrm{C} \times \mathrm{S}$ ), which is a plot of the integrity (C) and the damage (S) of the specimens until failure. All the tests were conducted at $20^{\circ} \mathrm{C}$.

It is important to recognize that both the MSCR and the LAS tests, in the present study, are not applied with their original purposes of binder performance evaluation. They are applied here as tools to characterize the heterogeneity between each of the extraction steps in different loading situations, and not to predict field rutting or fatigue of the materials.

\section{RESULTS AND DISCUSSION}

\subsection{Temperature-frequency sweep}

Master curves of $\left|\mathrm{G}^{*}\right|$ and $\delta$ constructed as result of the temperature-frequency sweep tests for the binders obtained in each of the extraction steps are shown in Figure 4 and Figure 5, respectively. For the WMA 25\% RAP mixture, it is possible to observe that the binder becomes stiffer as the extraction process goes on, what is consistent with the hypothesis that the latter stages of extraction (inner layers of binder) contain higher amounts of RAP binder due to the partial blending between binders. The binder obtained in Step 1 shows lower values of $\left|G^{*}\right|$, and this parameter tends to increase in Step 2, and even more in Step 3, as the amount of RAP binder increases. This difference between layers of binder is also observed in the shape of the $\left|G^{*}\right|$ master curve, which becomes flatter as the amount of RAP binder increases. This happens because more oxidized materials show a more gradual transition from elastic behavior to steadystate flow, what translates in a flatter master curve (Mogawer et al., 2017). Due to this change in the shape of the master curves, the difference of stiffness between the binders is more pronounced in the low-frequency end of the master curves, which is also related to higher temperatures.

Since the difference in behavior between the binders of each extraction step is attributed to the presence of different amounts of RAP binder, it was expected that the binders obtained in the staged extraction of the WMA 0\% RAP mixture showed no heterogeneity, since this mixture contained only fresh binder. However, what could be observed were slightly higher values of $\left|\mathrm{G}^{*}\right|$ and lower values of $\delta$ for the binder obtained in Step 3, while binders obtained in Step 1 and Step 2 showed very comparable behavior. These results indicate that other factors might be involved in the heterogeneity of the binder film that covers the aggregates in an asphalt mixture, and not only the presence of RAP, what is also discussed further in this paper.

Although slight differences can be visually observed in the master curves, it is difficult to analyze them since the master curves are plotted using a log-log scale. In order to better discern the linear viscoelastic properties obtained in each step of extraction, for both mixtures, the percent variation of the parameters $\left|\mathrm{G}^{*}\right|$ and $\delta$ was determined for different frequencies, in relation to the average values obtained in Step 1 . Then, it was possible to quantify the differences observed between the master curves, as presented in Figure 6. 


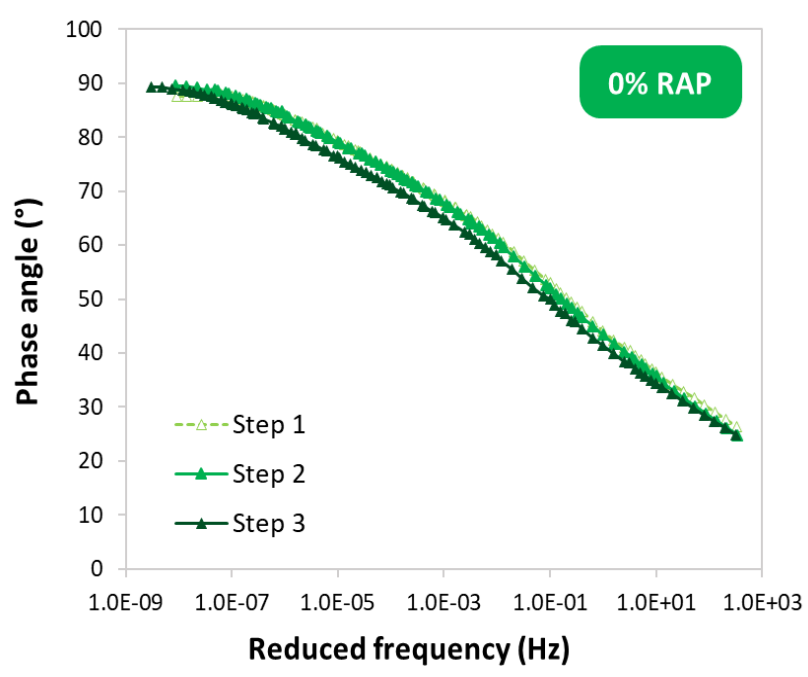

(a)

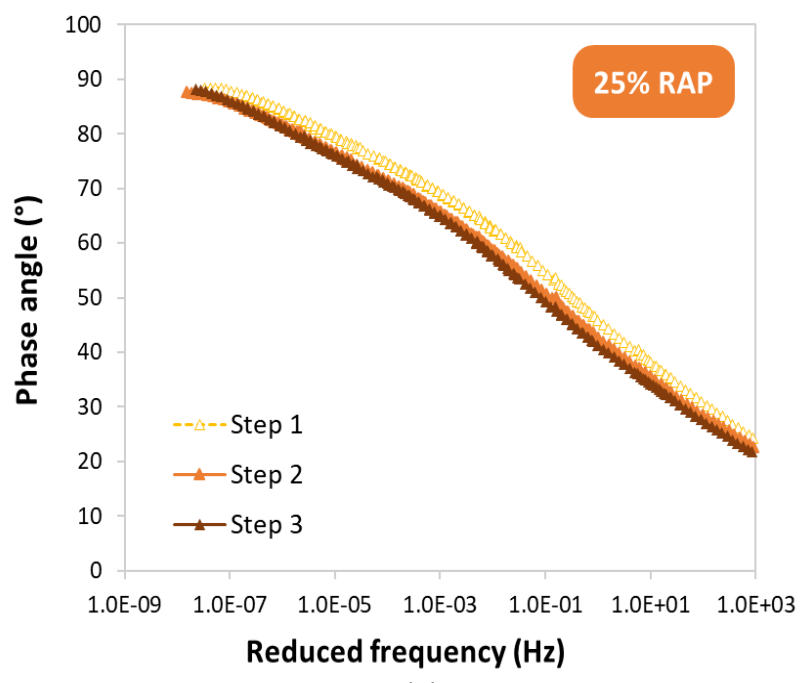

(b)

Figure 5. Master curves (at $15^{\circ} \mathrm{C}$ ) of phase angle for the binders obtained at each step of extraction for (A) WMA $0 \%$ RAP and (B) WMA 25\% RAP.

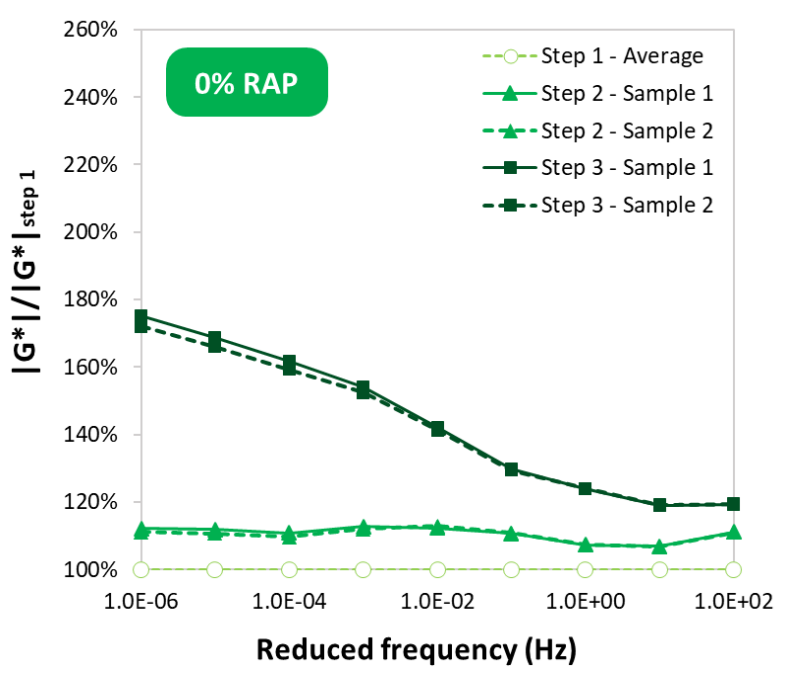

(a)

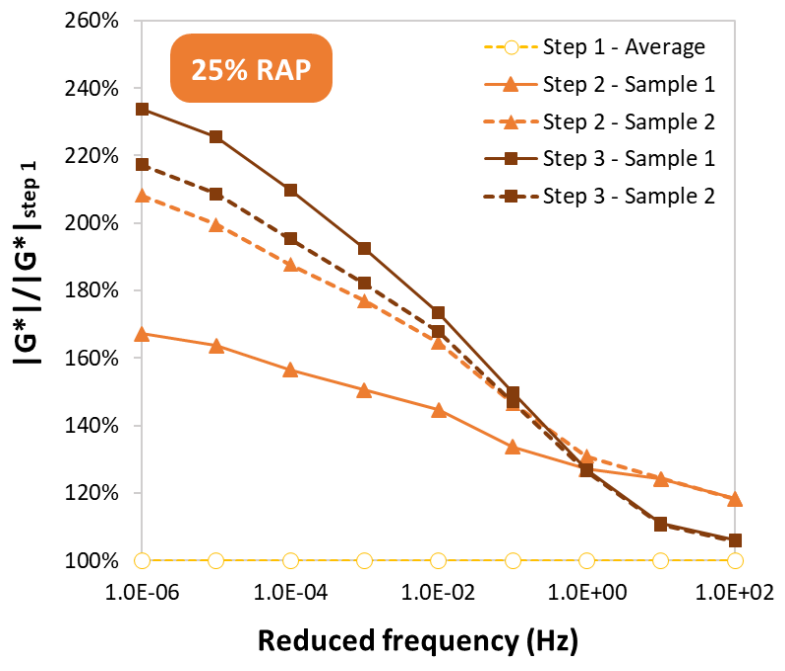

(c)

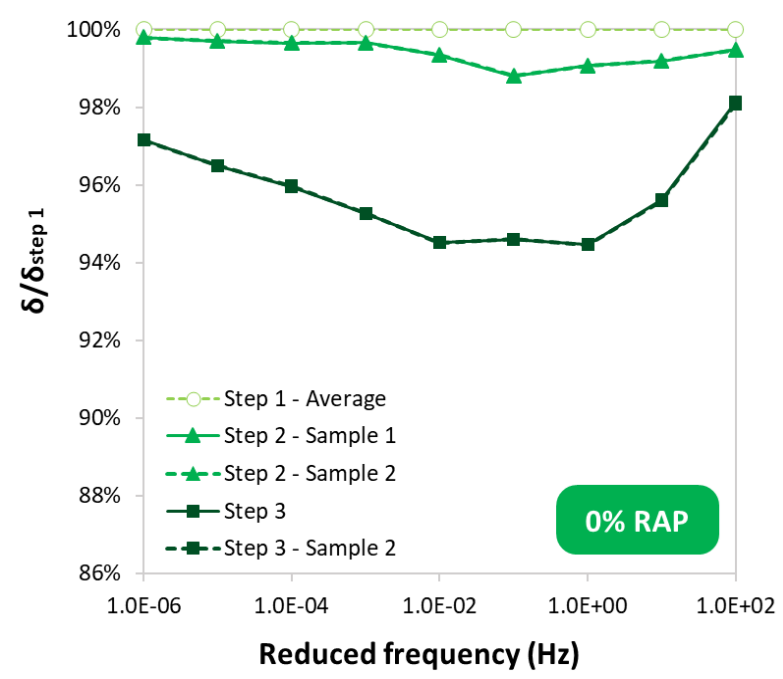

(b)

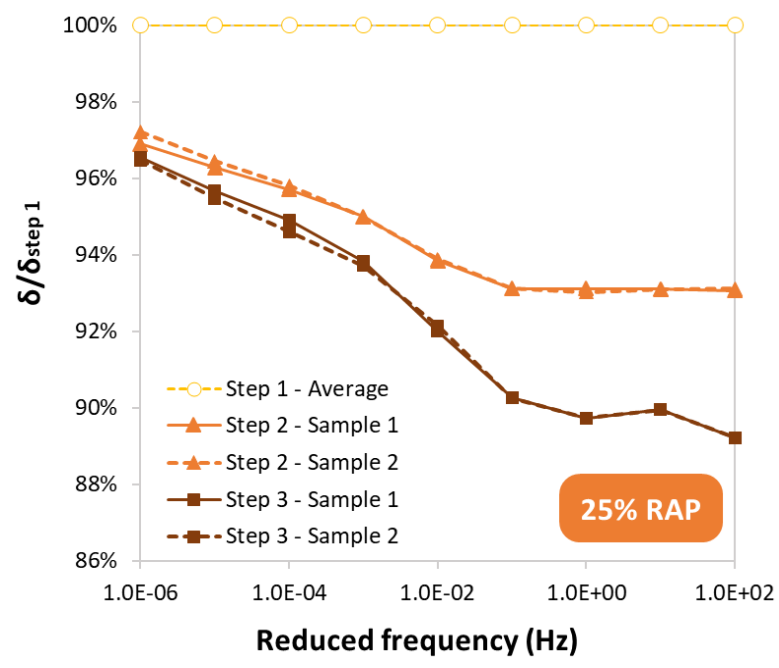

(d)

Figure 6. Percent variation in each extraction step, of (a) $\left|G^{*}\right|$, in WMA $0 \%$ RAP mixture, (b) $\delta$, in WMA $0 \%$ RAP mixture, (c) $\left|G^{*}\right|$, in WMA 25\% RAP mixture, and (d) $\delta$, in WMA 25\% RAP mixture, in relation to step 1 


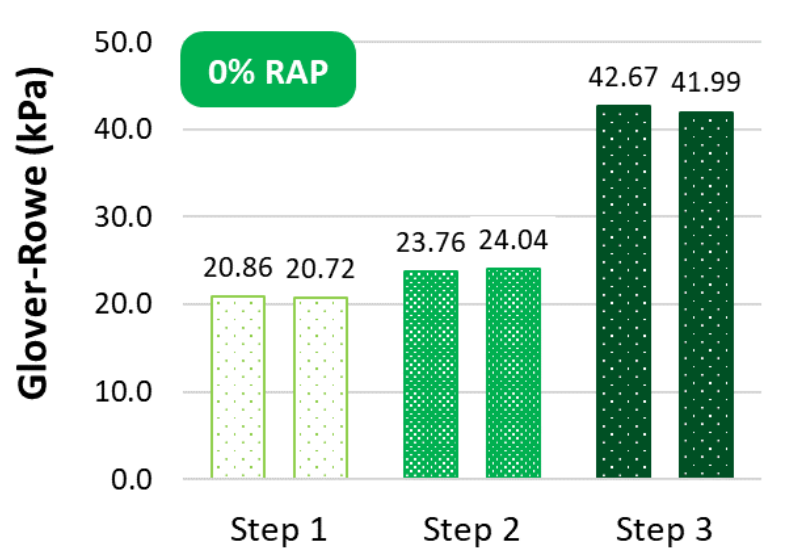

(a)

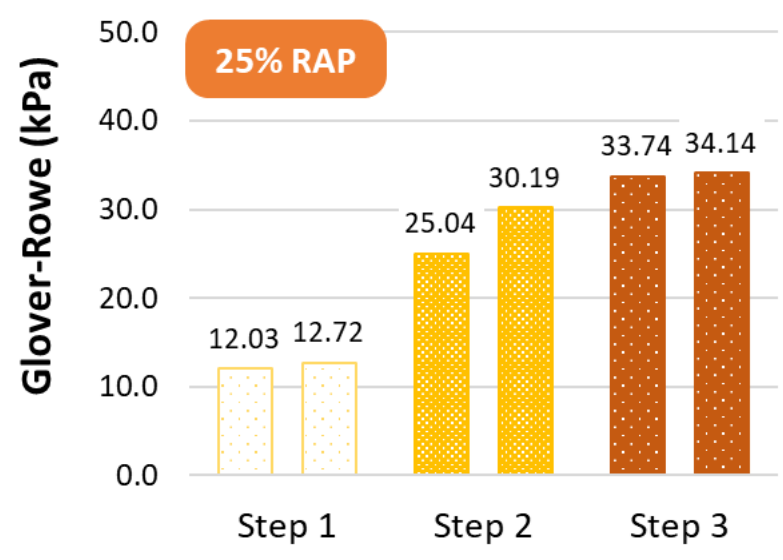

(b)

Figure 7. Results of the Glover-Rowe parameter for (A) WMA $0 \%$ RAP and (B) WMA $25 \%$ RAP

The results show that the heterogeneity between layers in the WMA 25\% RAP mixture was considerably higher than that observed for the WMA 0\% RAP mixture, proving that the presence of RAP can be identified by the staged extraction procedure. On the WMA $0 \%$ RAP mixture, the binders obtained in Step 1 and Step 2 were very similar, while the binder obtained in Step 3 was almost $80 \%$ stiffer (higher $\left|G^{*}\right|$ ) than the others, for the lowest frequency analyzed. The phase angle was also affected, reaching values that were around 5\% lower. The WMA 25\% RAP, in its turn, showed a more pronounced difference between the extracted layers of binder, reaching values of $\left|G^{*}\right|$ that were almost $140 \%$ higher in the lower frequencies and values of $\delta$ that were more than $10 \%$ lower, for the higher frequencies. For this mixture, there was a considerable difference of behavior between binders obtained in Step 1 and Step 2, what was not observed in the WMA 0\% RAP mix. The results of this analysis also confirmed that the binder behavior is more affected in lower frequencies, or higher temperatures.

Another useful tool to analyze the results of the frequency-sweep tests is the Glover-Rowe parameter, which is calculated with stiffness and phase angle measurements at a temperature of $15^{\circ} \mathrm{C}$ and a frequency of $0.005 \mathrm{rad} / \mathrm{s}$. This parameter was developed as described by Rowe $e t$ al. (2014), and it is a rheological metric which has been used to monitor the effects of oxidation in asphalt binders. The Glover-Rowe parameter was calculated for each of the analyzed samples of asphalt binder (two samples for each step of extraction), and the results are presented in Figure 7. The values obtained followed the same trend that was visually detected on the master curves. For the WMA 0\% RAP mixture, the binder obtained in Step 3 had considerably higher results than the first two extraction steps, which were very close to each other. As for the WMA $25 \%$ RAP mixture, the results showed a more gradual increase of the Glover-Rowe parameter through the extraction procedure, what can be explained by the incomplete and gradual blending between RAP binder and virgin binder.

\subsection{MSCR test}

Results of Jnr from the MSCR tests are shown in Figure 8 for both stress levels applied $(0.1$ and $3.2 \mathrm{kPa}$ ). Percent recovery was equal to zero for all samples. The Jnr results for the WMA 25\% RAP mixture showed the same trend that was observed for the other tests, with a gradual variation of the parameter at each extraction step. In this case the parameter was higher for the 
binder obtained in Step 1 and was progressively reduced for the binders obtained in Steps 2 and 3. Binders with higher amount of RAP binder in their composition are expected to show lower Jnr values, as the RAP binder is less deformable due to aging, what was consistent with the results.

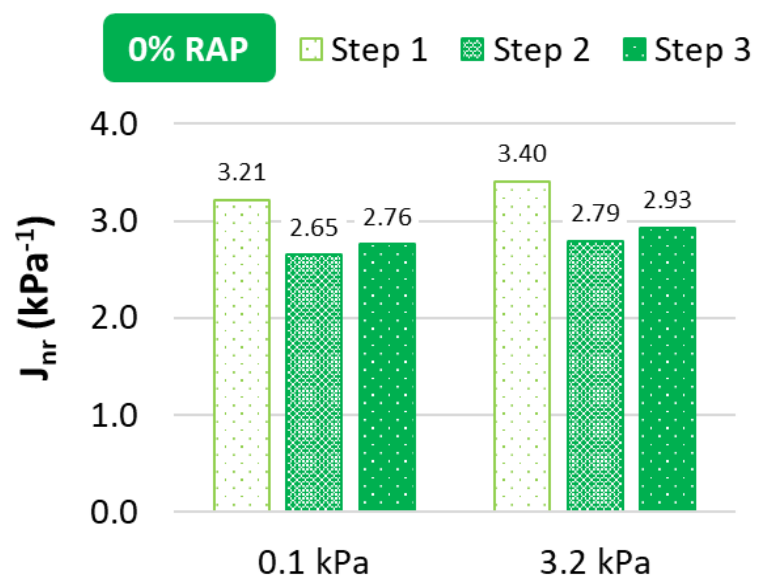

(a)

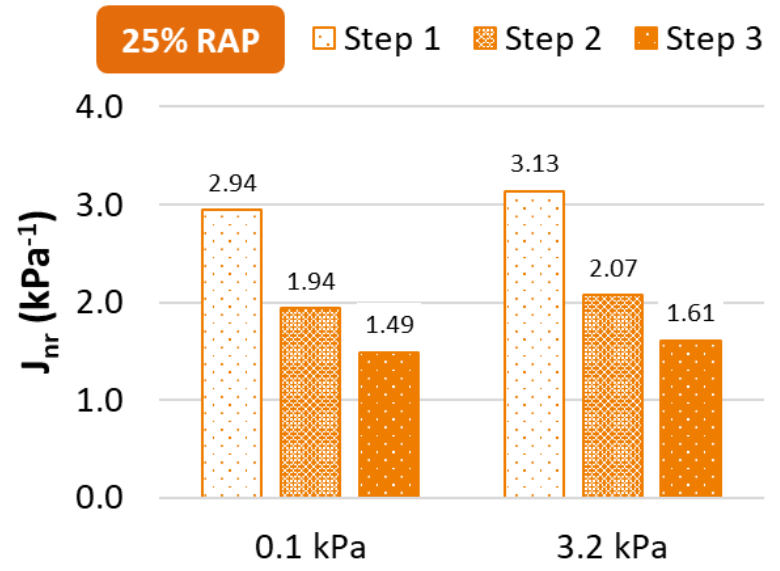

(b)

Figure 8. Results of the MSCR test for (a) WMA 0\% RAP and (b) WMA 25\% RAP

The $0 \%$ RAP mixture, in turn, had a very small variation of the parameter at each step, as it was expected because of the absence of RAP in this mixture. Differently from what was observed in the other tests conducted, the binder recovered from Step 3 was not considerably different from the binders obtained in steps 1 and 2, and therefore a more pronounced homogeneity was observed using the MSCR test. The binder obtained for the 0\% RAP mixture in Step 3 had higher stiffness in the linear elastic region, according to the results of the temperature-frequency sweep tests, but this increased stiffness was not equivalent to a lower non-recoverable compliance in the MSCR test, outside of the linear viscoelastic region. This fact supports the hypothesis that the higher $\left|\mathrm{G}^{*}\right|$ and lower $\delta$ values for the Step 3 binder of the $0 \%$ RAP mixture (which also led to a higher value for the Glover-Rowe parameter) were caused by a factor that did not interfere with the MSCR test results (further investigated in this paper), while for the 25\% RAP mixture, the variation of the linear viscoelastic parameters was caused by the presence of different amounts of RAP binder, which is a factor that affected the MSCR results. Therefore, the MSCR test seems to be an analysis method that is able to capture the presence of RAP more efficiently and evaluate binder homogeneity and blending.

\subsection{LAS test}

Figure 9 presents the main outcome of the LAS test, a curve expressing fatigue life in cycles $\left(\mathrm{N}_{\mathrm{f}}\right)$ as a function of strain level, together with the damage characteristic curves obtained, for each of the studied mixtures binders. Although a lower fatigue life is usually associated with an increased stiffness, Harvey and Tsai (1997) concluded in their study that a high stiffness caused by long-term aging does not necessarily compromise fatigue life, and this same conclusion can be drawn from the present results. The trends that were observed in the previous tests were not clearly present in the results of the LAS test, although a variation in the slope of the curves is perceived. 


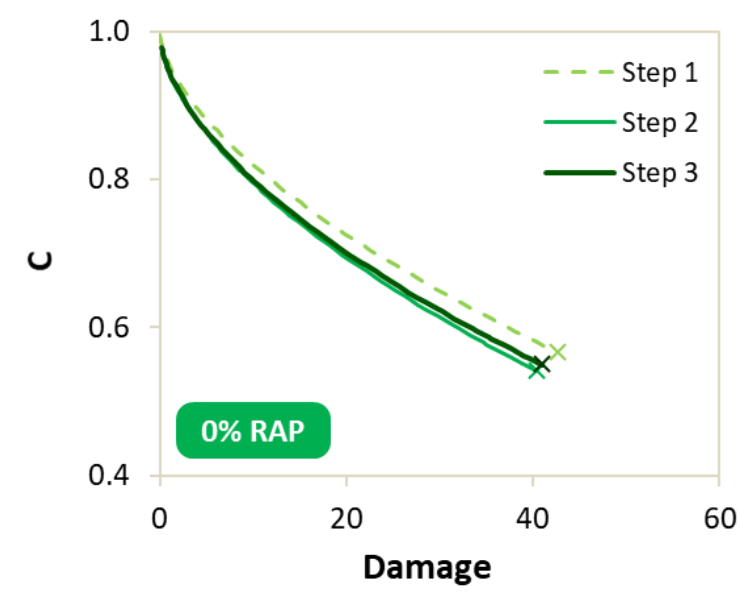

(a)

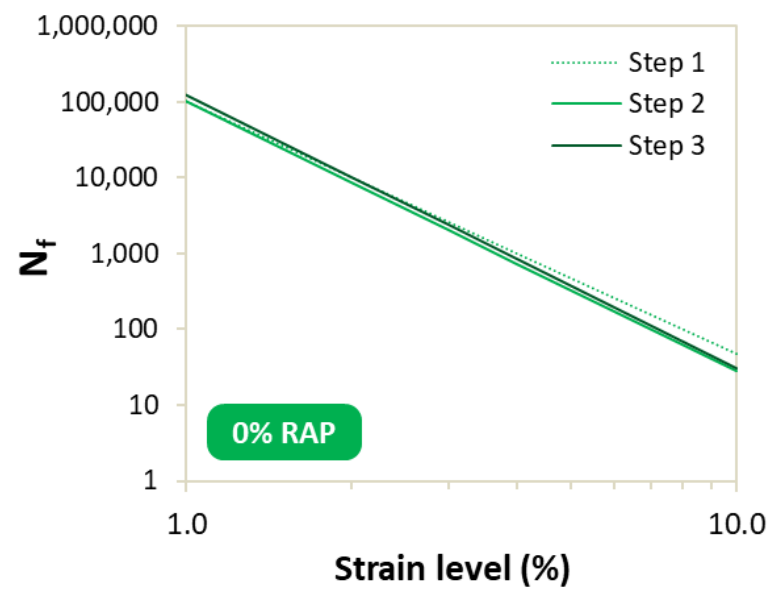

(c)

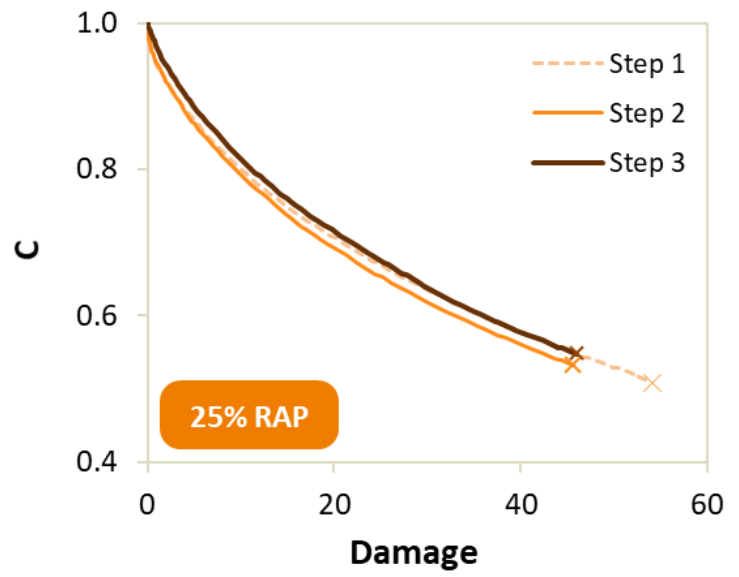

(b)

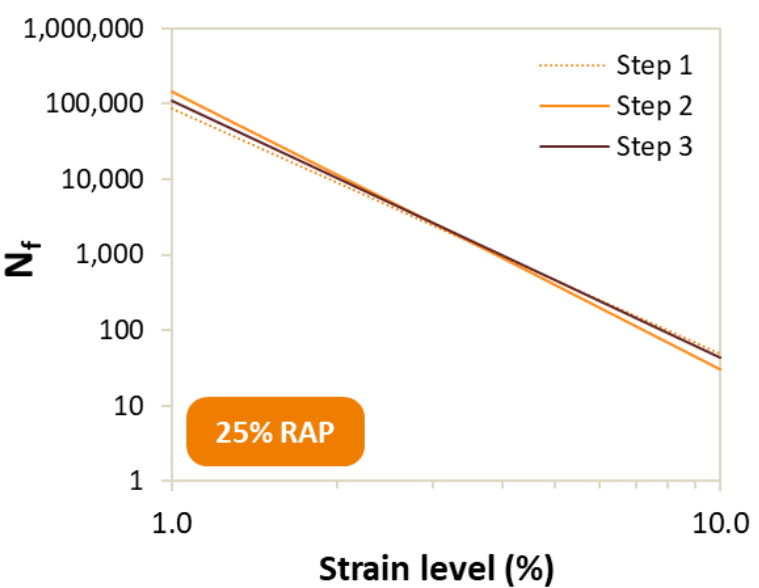

(d)

Figure 9. Results of the LAS test: damage characteristic curves for (a) WMA 0\% RAP and (b) WMA 25\% RAP, and fatigue life curves for (c) WMA 0\% RAP and (d) WMA 25\% RAP

Another method to interpret the results of the LAS test is to calculate the FFL parameter, proposed by Martins (2014). This parameter is equal to the area underneath the fatigue life curve, between the strain levels of $1.25 \%$ and $2.5 \%$, and can be calculated using Equation 1 . The results, presented in Table 2 , show that even using this parameter it is not possible to observe a clear trend, as it was possible in the previous tests.

$$
F F L=\frac{\left(\log \left(N_{f, 1.25 \%}\right)+\log \left(N_{f, 2.5 \%}\right)\right)}{2} \times(\log (0.025)-\log (0.0125))
$$

Table 2 - Results of the FFL parameter, proposed by Martins (2014)

\begin{tabular}{llll}
\hline Mixture & Step 1 & Step 2 & Step 3 \\
\hline WMA 0\% RAP & 1.258 & 1.244 & 1.258 \\
WMA 25\% RAP & 1.244 & 1.282 & 1.264 \\
\hline
\end{tabular}

The heterogeneity between binder layers that was observed in the previous results could not be identified with the LAS test. This can be associated to the fact that the difference of behavior in the linear viscoelastic region was more evident for higher temperatures, as it was concluded by the temperature and frequency sweep tests, and the LAS tests were conducted at $20^{\circ} \mathrm{C}$. 
The presence of RAP affects the behavior of the asphalt mixture in different ways, and it is very often related to the reduction of fatigue life. That happens because the oxidized binder in RAP makes the mixture stiffer and more susceptible to cracking, what can become a serious problem for field performance, especially at low temperatures. However, the behavior at higher temperatures is also affected, but in a positive way, as the resistance to rutting increases. In the present study, this second effect was more pronounced than the first, being identified more clearly by the rheological tests (especially the MSCR), and being more adequate to calculate de degree of blending between binders.

\subsection{Ash content evaluation}

Aiming to investigate other factors that could have affected the results of rheological tests, all the binders obtained on the staged extraction procedure for both mixtures were tested following the procedure ASTM D8078-16 for determination of ash content. This test is useful to determine if finer residues of the aggregates remained in the recovered binders after extraction, what might affect the accuracy of measured properties. Results are presented in Figure 10 and indicate that only the binder obtained in Step 3 for the 0\% RAP mixture showed high ash content, of 1.75\%. According to the standard ASTM D1856-09, ash contents of recovered asphalts greater than $1 \%$ may affect the accuracy of other test results, and that might be the case for the binder obtained in Step 3 of the WMA 0\% RAP mixture, what would explain the higher values of $\left|G^{*}\right|$ and lower values of $\delta$ observed, in relation to Steps 1 and 2 of the same mixture. That could explain also the elevated result for the Glover-Rowe parameter in Step 3 of the 0\% RAP mixture, since it is calculated using both $\left|\mathrm{G}^{*}\right|$ and $\delta$. All the other binders had ash content values below the $1 \%$ limit, so their rheological behavior should not be affected by the ash content. It is important to emphasize that other factors might be involved in this result as well, such as a possible burning of the asphalt binder when it got in contact with the aggregates, and further investigations should be conducted before confirming this hypothesis.

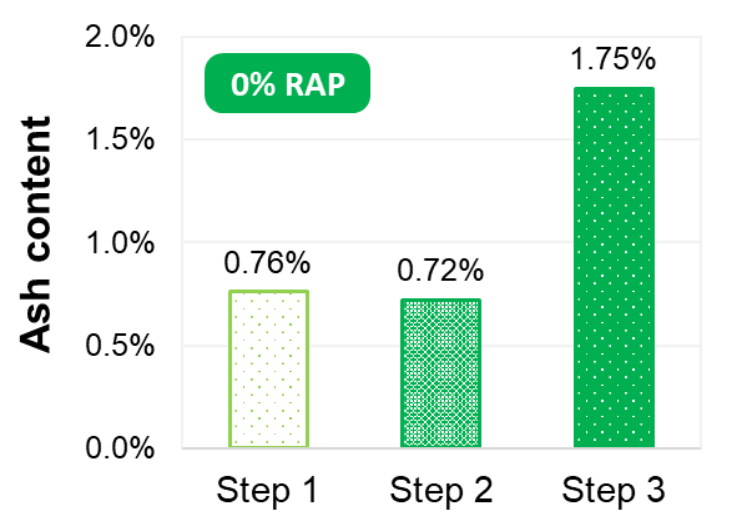

(a)

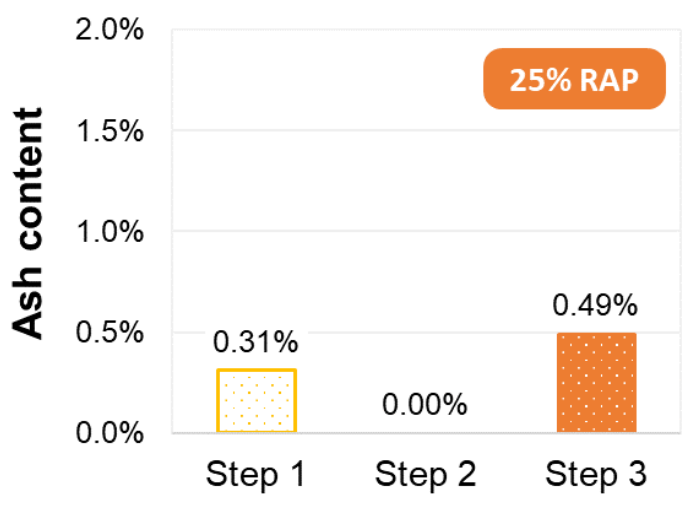

(b)

Figure 10. Results of the ash content test for (a) WMA 0\% RAP and (b) WMA 25\% RAP

\section{SUMMARY AND CONCLUSIONS}

This paper describes the application of a staged extraction laboratory procedure aiming to evaluate the blending between fresh binder and RAP binder in a plant-produced warm recycled mixture with 25\% RAP (WMA 25\% RAP) and a control mixture without RAP (WMA 0\% RAP). 
The following conclusions could be drawn, based on the results obtained:

- When applying the proposed extraction method, it is important to adjust the length of the extraction steps, in order to divide the binder in three layers of approximately the same amount of binder (in terms of weight), improving the distinction between layers and ensuring a minimum amount of binder in each of them. This way, homogeneity between layers can be better evaluated, and that is related to the level of binder blending within the mixture.

- Master curves of dynamic shear modulus and phase angle, including the analysis of the Glover-Rowe parameter, are suitable to recognize the different behaviors of each layer of asphalt binder obtained (especially at higher temperatures, or lower frequencies), as higher amounts of blended RAP binder result in a higher modulus, a flatter modulus master curve, and a lower phase angle. However, the rheological parameter that best captured the different behavior of the binder layers was the non-recoverable compliance (Jnr) from the MSCR test. On the other hand, the results of the LAS test were not so useful for distinguishing the binder layers.

- Heterogeneity between layers was observed also in the control mixture WMA 0\% RAP, especially in the results of temperature-frequency sweep tests, even though there was only virgin binder in that mixture. This fact highlights that the presence of RAP is not the only factor that may affect binder homogeneity, and that must be considered when analyzing the results of the staged extraction procedure. In the present study, however, the results for the Step 3 binder of the WMA 0\% RAP mixture can be justified by a considerably higher ash content, what resulted in higher values of dynamic shear modulus, lower phase angles and an increased Glover-Rowe parameter, and was not observed on the results for the WMA 25\% RAP mixture. Moreover, the heterogeneity observed in the temperature-frequency sweep tests for the 0\% RAP mix was not observed in the MSCR test results, while for the 25\% RAP mix the results of both tests followed the same trend and can be attributed to the partial blending between virgin binder and RAP binder.

- Although further studies are necessary to confirm that, the staged extraction procedure associated with rheological tests, aiming to analyze the heterogeneity of the extracted layers, seems to be a promising solution to determine the degree of blending between fresh binder and RAP binder on hot and warm recycled mixtures.

\section{REFERENCES}

Bowers, B. F.; J. Moore; B. Huang and X. Shu (2014a) Blending efficiency of Reclaimed Asphalt Pavement: An approach utilizing rheological properties and molecular weight distributions. Fuel, v. 135, p. 63-68. D0I:10.1016/j.fuel.2014.05.059

Bowers, B. F.; B. Huang and X. Shu (2014b) Refining laboratory procedure for artificial RAP: A comparative study. Construction and Building Materials, v. 52, p. 385-390. DOI: 10.1016/j.conbuildmat.2013.11.003

Bowers, B. F.; B. Huang; Q. He; X. Shu; X. Jia and B. C. Miller (2015) Investigation of Sequential Dissolution of Asphalt Binder in Common Solvents by FTIR and Binder Fractionation. Journal of Materials in Civil Engineering, v. 27. DOI:10.1061/(ASCE)MT.1943-5533.0001198

Carpenter, S. H. and J. R. Wolosick (1980) Modifier influence in the charaterization of hot-mix recycled material. Transportation Research Record, v. 777, p. 15-22.

Copeland, A. (2011) Reclaimed Asphalt Pavement in Asphalt Mixtures: State of the Practice. Report No. FHWA-HRT-11-021, McLean, VA.

Eddhahak-Ouni, A.; A. Dony; J. Colin; J. Navaro; I. Drouadaine and D. Bruneau (2012) Experimental investigation of the homogeneity of the blended binder of a high rate recycled asphalt. Road Materials and Pavement Design, v. 13, p. 37-41. DOI:10.1080/14680629.2012.700269

Gaspar, M. S.; K. L. Vasconcelos; D. Lo Presti and L. L. B. Bernucci (2017) Procedimento de extração em etapas para avaliação da interação entre ligantes na reciclagem a quente e morna. Proceedings of the XIX Congreso Latinoamericano del Asfalto, Medellín, Colombia. 
Gaspar, M. S.; M. Lopes; K. L. Vasconcelos; P. C. Vasconcellos and L. L. B. Bernucci (2019) Experimental application of warmmix technique for recycled asphalt mixtures using conventional batch plants. In: $98^{\text {th }}$ Transportation Research Board Annual Meeting, Washington, D.C.

Gennesseaux, M. M. L. (2015) Avaliação da durabilidade de misturas asfálticas a quente e mornas contendo material asfáltico fresado. Doctoral thesis, Universidade de São Paulo.

Harvey, J. and B. Tsai (1997) Long-Term Oven-Aging Effects on Fatigue and Initial Stiffness of Asphalt Concrete. Transportation Research Record, vol. 1590.

Huang, B.; G. Li; D. Vukosavljevic, X. Shu and B. Egan (2005) Laboratory Investigation of Mixing Hot-Mix Asphalt with Reclaimed Asphalt Pavement. Transportation Research Record, v. 1929, p. 37-45. DOI:10.3141/1929-05

Lo Presti, D.; A. Jiménez del Barco Carrión; G. Airey and E. Hajj (2016) Towards 100\% recycling of reclaimed asphalt in road surface courses: binder design methodology and case studies. Journal of Cleaner Production, v. 131, p. 43-51. DOI:10.1016/j.jclepro.2016.05.093

Lopes, M.; A. Siqueira; L. Bernucci; E. Moura; E. Shoji and M. C. Junior (2016) Avaliação laboratorial da tecnologia de reciclagem morna com incorporação de elevadas taxas de material fresado. In: $22^{\circ}$ Encontro de Asfalto, Rio de Janeiro.

Martins, A. T. (2014) Contribuição para a validação do ensaio de resistência ao dano por fadiga para ligantes asfálticos. Master's dissertation, Universidade Federal do Rio de Janeiro.

Mogawer, W. S.; A. Austerman; I. L. Al-Qadi; W. Buttlar; H. Ozer and B. Hill (2017) Using binder and mixture space diagrams to evaluate the effect of re-refined engine oil bottoms on binders and mixtures after ageing. Road Materials and Pavement Design, v. 18, p. 154-182. DOI:10.1080/14680629.2016.1266756

Navaro, J.; D. Bruneau; I. Douadaine; J. Colin and J. Cournet (2012) Observation and evaluation of the degree of blending of reclaimed asphalt concretes using microscopy image analysis. Construction and Building Materials, v. 37, p. 135-143. DOI: 10.1016/j.conbuildmat.2012.07.048

Noureldin, A. S. and L. E. Wood (1987) Rejuvenator Diffusion in Binder Film for Hot-Mix Recycled Asphalt Pavement. Transportation Research Record, v. 1115, p. 51-61.

Rowe, G. M.; G. King and M. Anderson (2014) The Influence of Binder Rheology on the Cracking of Asphalt Mixes in Airport and Highway Projects. Journal of Testing and Evaluation, vol. 42. DOI:10.1520/JTE20130245

Shirodkar, P.; Y. Mehta; A. Nolan; K. Sonpal; C. Tomlinson; E. Dubois; P. Sullivan and R. Sauber (2011) A study to determine the degree of partial blending of reclaimed asphalt pavement (RAP) binder for high RAP hot mix asphalt. Construction and Building Materials, v. 25, p. 150-155. DOI:10.1016/j.conbuildmat.2010.06.045

Soleymani, H. R.; M. Anderson; R. McDaniel and M. Abdelrahman (2000) Journal of the Association of Asphalt Paving Technologists, v. 69, p. 366-390.

Zaumanis, M. and R. B. Mallick (2015) Review of very high-content reclaimed asphalt use in plant-produced pavements: state of the art. International Journal of Pavement Engineering, v. 16, p. 39-55. DOI:10.1080/10298436.2014.893331

Zearley, L. J. (1979) Penetration characteristics of asphalt in a recycled mixture. Iowa Department of Transportation Highway Division. Ames, IA.

Zhao S.; B. Huang; X. Shu and M. E. Woods (2015a) Quantitative Characterization of Binder Blending: How Much RAP / RAS Binder Is Mobilized during Mixing? Transportation Research Record, v. 2506, p. 72-80. DOI:10.3141/2506-08

Zhao, S.; B. Huang and X. Shu (2015b) Investigation on binder homogeneity of RAP/RAS mixtures through staged extraction. Construction and Building Materials, v. 82, p. 184-191. DOI:10.1016/j.conbuildmat.2015.02.013 